\title{
SUBTALAR JOINT IN NEUTRAL AND RELAXED POSITIONS FOR EVALUATION OF MEDIAL LONGITUDINAL ARCH
}

\section{ARTICULAÇÃO SUBTALAR EM POSIÇÕES NEUTRA E RELAXADA PARA AVALIAÇÃO DO ARCO LONGITUDINAL MEDIAL}

\author{
andré Setti Persiane ${ }^{1,2}$ (1), Daiane Magalhães Gomes Negrão ${ }^{1}$ (1), Raone Daltro Paraguassu alves ${ }^{1}$ (1),

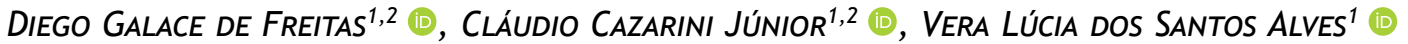 \\ 1. Faculdade de Ciências Médicas da Santa Casa de São Paulo, São Paulo, SP, Brazil. \\ 2. Universidade Paulista (UNIP), São Paulo, SP, Brazil.
}

\section{ABSTRACT}

Objective: The medial longitudinal arch is the main structure of load bearing and shock absorption of the foot. The evaluation of medial longitudinal arch, such as the navicular height, the medial longitudinal arch angle and the Feiss line should be performed with the subtalar joint in the neutral and relaxed position. Our study analyzed the correlation between the measurements of the subtalar joint in neutral and relaxed positions during the evaluation tests of the medial longitudinal arch. Methods: This is a cross-sectional study, in which 51 healthy volunteers (102 feet; 36 women; $28 \pm 5$ years, $1.66 \pm 0.10 \mathrm{~m} ; 24.5 \pm 4.5 \mathrm{~kg} / \mathrm{m} 2)$ had their navicular height, medial longitudinal arch angle and Feiss line measured in the neutral and relaxed positions. The correlation between the measures was evaluated using Pearson's test. Results: A strong correlation of the 102 feet Feiss line measurements between neutral and relaxed positions $(r=0.81)$ was observed, and a moderate correlation between the medial longitudinal arch angle $(r=0.78)$ and between navicular height in neutral and relaxed positions $(r=0.76)$. Conclusion: The measurements of the longitudinal medial arch between the neutral and relaxed positions are strongly correlated. Therefore, it is not necessary to measure the medial longitudinal arch in both neutral and relaxed positions. Level of Evidence II, Diagnostic Studies Investigating a diagnostic test.

Keywords: Ankle. Flatfoot. Foot. Foot Deformities. Talipes Cavus. Tarsal Bones.

\section{RESUMO}

Objetivo: O arco longitudinal medial é a estrutura principal para suporte de carga e absorção de impacto no pé. Medidas para avaliação do arco longitudinal medial, como a altura navicular, o ângulo do arco longitudinal medial e a linha de Feiss devem ser realizadas com a articulação subtalar na posição neutra e relaxada. Este estudo analisou a correlação entre as medidas da articulação subtalar em posições neutra e relaxada durante os testes de avaliação do arco longitudinal medial. Métodos: Neste estudo transversal, 51 voluntários saudáveis (102 pés; 36 mulheres; $28 \pm 5$ anos, 1,66 $\pm 0,10 \mathrm{~m} ; 24,5 \pm 4,5 \mathrm{~kg} / \mathrm{m} 2)$ tiveram altura navicular, ângulo do arco longitudinal medial e linha de Feiss medida nas posições neutra e relaxada. A correlação entre eles foi avaliada pelo teste de Pearson. Resultados: Houve uma correlação muito forte das medidas de linha de Feiss de 102 pés entre a posição neutra e relaxada $(r=0,81)$ e uma correlação moderada entre o ângulo do arco longitudinal medial $(r=0,78)$ e altura navicular nas posições neutra e relaxada $(r=0,76)$. Conclusão: As medidas do arco medial longitudinal entre as posições neutra e relaxada estão fortemente correlacionadas. Não é necessário, portanto, medir o arco longitudinal medial nas posições neutra e relaxada. Nível de Evidência II, Estudos diagnósticos - Investigação de um exame para diagnóstico.

Descritores: Tornozelo. Pé Chato. Pé. Deformidades do Pé. Pé Cavo. Ossos do Tarso.

Citation: Persiane AS, Negrão DMG, Alves RDP, Freitas DG, Cazarini C Jr., Alves VLS. Subtalar joint in neutral and relaxed positions for evaluation of medial longitudinal arch. Acta Ortop Bras. [online]. 2021;29(4):177-180. Available from URL: http://www.scielo.br/aob.

\section{INTRODUCTION}

The biomechanics of the feet interfere with body posture and with the harmonious distribution of joint and plantar pressures, helping to walk within physiological patterns., ${ }^{1,2}$ The structure and movements of the arches of the foot are essential for the proper function of the body and well-being. ${ }^{3}$

The medial longitudinal arch (MLA) is the main load-bearing and shock-absorbing structure of the foot. Changes in MLA can cause pain and influence the biomechanics of the limb, leading

All authors declare no potential conflict of interest related to this article.

The study was conducted at Serviço de Fisioterapia da Irmandade da Santa Casa de Misericórdia de São Paulo.

Correspondence: Vera Lúcia dos Santos Alves. Rua Dr. Cesário Mota Júnior, 112, São Paulo, SP, Brazil, 01221020. fisioterapiasc@uol.com.br 
to further modifications in plantar pressures that are common in individuals suffering from pathologies in the feet and even in other joints of the lower limbs., ${ }^{4,5}$

The decrease in MLA height, characterized by pronation, reduces the stability of the foot during the support phase and the gait impulse. 6 This reduction leads to a decrease in blood flow in the calcaneus tendon,7 which is a risk factor for calcaneal tendinopathy 8 and plantar fasciitis, and it is a repetitive strain injury causing excessive deformation of the plantar arch. ${ }^{6-8}$

Several measures are used to evaluate the MLA, such as Feiss line $(\mathrm{FL}),{ }^{9}$ the navicular height $(\mathrm{NH}),{ }^{9}$ the medial longitudinal arch angle (MLAA) ${ }^{9}$ the arch index, ${ }^{10}$ the Foot Posture Index (FPI) ${ }^{11}$ and the relative arch deformity. ${ }^{12}$ The most common measurements used are the $\mathrm{FL}, \mathrm{NH}$ and MLAA. ${ }^{9}$

Two measurements have been recommended, the first with the subject sitting, with the subtalar joint in the neutral position and the second in a standing position with bipedal support with the foot relaxed. ${ }^{12,13}$ To our knowledge, there are no studies in the literature on the correlation between the measurements $(\mathrm{FL}, \mathrm{NH}$, MLAA) with the subtalar in a neutral and relaxed position. This comparison might be important for more specific and efficient assessments, reducing time and costs. Therefore, our study aimed to analyze the correlation between the measurements of the MLA in neutral and relaxed positions.

\section{MATERIALS AND METHODS}

\section{Study design and ethics}

This is a cross-sectional study, performed with healthy subjects recruited by the social media profile of a university hospital. The university review board (RB) approved the study protocol that was in accordance with the Helsinki Declaration, and all participants signed informed consent forms (RB protocol: 62766716.4.0000.5479).

\section{Participants}

Social media profiles from the university hospital were used to recruit participants for this study. The posts invited sedentary adults aged 18 to 40 years and without any feet pain or other symptoms to participate and be evaluated by a physical therapist. Individuals would be excluded if, in the first assessment, they reported a history of feet pain or injury, any lower limb fracture, any muscle or joint lesion or lower limb surgery in the past 12 months, back pain in the last 12 months, rigid flat feet, calcaneus valgus above $10^{\circ}$, or a history of neurological abnormalities. For this initial evaluation, the subjects filled a questionnaire on the demographic and clinical history, including past injuries to the foot.

\section{Evaluation procedures}

The same physical therapist, who had five years of experience in orthopedic physical therapy, evaluated all participants between January and July 2017. The training was conducted twice a week for two weeks. The evaluator was trained in the palpation of anatomical structures, how to identify the reference points, the different measurements and the most frequent measurement errors. However, the physical therapist was not informed about the use of the measures, with the purpose to blind for the study objectives.

The evaluator analyzed ten subjects healthy in the pilot study twice, with a one-week interval, so that between-day reliability could be estimated. If the intraclass correlation coefficient (ICC) were $<0.4$, the evaluation would not be selected for the study. First, the evaluator measured the calcaneus angle, with the patient lying in a prone position with feet off the bed. He palpated the calcaneus medially and laterally palpated and the inferior and medial aspects of the calcaneus were identified with dots with a marking pen. A line connected the dots, bisecting the calcaneus. The examiner then identified the subtalar neutral by palpating the patient's talus, feeling both medial and lateral aspects equally. He used the goniometer to measure the varus or valgus of the calcaneus. ${ }^{14}$

With the participant sitting on a chair, with hips, knees and ankle bent in $90^{\circ}$, the evaluator identified the following anatomical points using the marker pen: the center of the medial malleolus, the navicular tuberosity and the head of the first metatarsal. Next, the evaluator palpated the lateral and medial aspects of the talus, maintaining the subtalar joint in a neutral position, and then performed the following measurements: MLA angle (MLAA), navicular height $(\mathrm{NH})$ and Feiss line $(\mathrm{FL})$, in this sequence. With the participant now in the standing position, with bipedal support, the evaluator again performed the MLAA, NH and FL measurements with the subtalar joint in a relaxed position.

The evaluator used a goniometer with a transparent plastic protractor $\left(0^{\circ}\right.$ to $\left.360^{\circ}\right)$ with two $20 \mathrm{~cm}$ rulers for the measurements (SH5205, Carci, São Paulo, Brazil); and a transparent ruler $(0 \mathrm{~cm}$ to $30 \mathrm{~cm}$; Ruler $30 \mathrm{~cm}$, Acrimet, São Bernardo do Campo, Brazil). For the $\mathrm{NH}$, the evaluator measured the distance from the floor to the navicular tuberosity. ${ }^{9}$ For the $\mathrm{FL}$, the evaluator traced a line between the center of the medial malleolus and the head of the first metatarsal. Next, the evaluator used a ruler to measure the perpendicular distance in centimeters between the tubercle of the navicular and the line of the medial malleolus to the head of the first metatarsal. If the tuberosity of the navicular was above the line, the measurement was considered as positive. If the navicular tuberosity was below the line, the value was negative. ${ }^{9}$ To measure the MLAA, the evaluator placed the center of the goniometer on the navicular tuberosity, so that the goniometer extremities could indicate the center of the medial malleolus and the head of the first metatarsus. ${ }^{9}$ Typical values for $\mathrm{NH}$ are between 3.6 and $5.5 \mathrm{~cm}$, for MLAA between $130^{\circ}$ and $152^{\circ}$ and for $\mathrm{FL}$ between -2.6 and $1.2 \mathrm{~cm} .{ }^{9}$ Figure 1 shows the measurement technique.

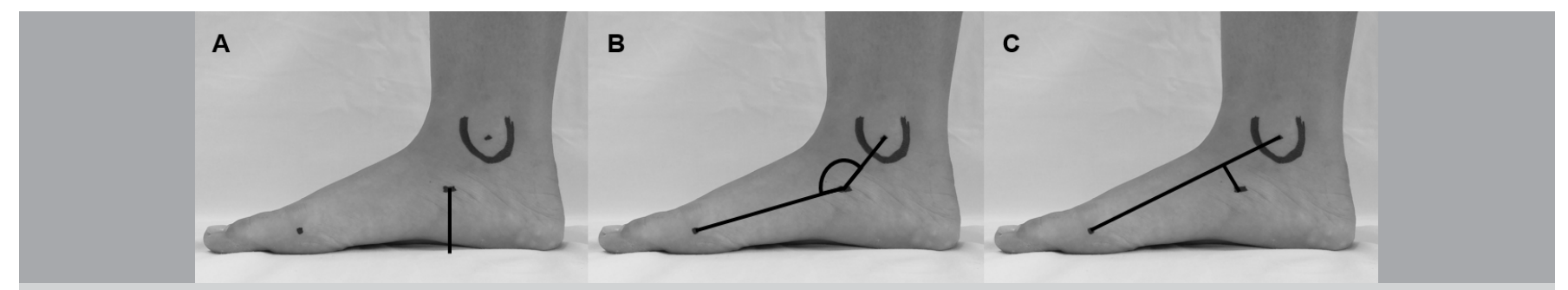

Figure 1. Measurement technique of the medial longitudinal arch (MLA). A: Navicular height; B: medial longitudinal arch angle; C: Feiss line. 


\section{Sample size and statistical analysis}

Ten participants were used as a pilot evaluation to estimate the sample size. This estimating was based on Pearson's correlation analysis between measurements in neutral and relaxed positions, adopting a correlation of at least 0.4 , with an alpha of $5 \%$ and power of $80 \%$. The estimating revealed that 47 participants would be necessary.

The ten participants of the study were tested on 2 occasions separated by 7 days to determine the test-retest reliability of the ALM measurement. For standard error measurement (SEM), the standard difference (SD) between measurement of first and second day (test score-retest score $=$ difference) were estimated. Next, the obtained SD was multiplied by the square root $(1-I C C)$.

The intraclass correlation coefficient (ICC) and standard error of measurement (SEM) were 0.98 and $0.15^{\circ}$ for MLAA for neutral positions, 0.98 and $0.11^{\circ}$ for MLAA for relaxed positions, 0.97 and $0.02 \mathrm{~cm}$ for $\mathrm{NH}$ neutral positions, 0.92 and $0.06 \mathrm{~cm}$ for $\mathrm{NH}$ for relaxed positions, 0.89 and $0.07 \mathrm{~cm}$ for $\mathrm{FL}$ for neutral positions and 0.93 and $0.05 \mathrm{~cm}$ for FL relaxed positions.

The Shapiro-Wilk test was used for homogeneity distribution, and a $5 \%$ significance level was used, in which the values presented a normal distribution.

Pearson's correlation was used for the analysis of correlation between neutral and relaxed positions. For the interpretation of the Pearson's correlation, 1 was used as the perfect correlation, 0.8 to 0.9 as very strong, 0.6 to 0.7 as moderate, 0.3 to 0.5 as fair, 0.1 to 0.2 as poor and 0 as none. Data were analyzed using SPSS software version 20 (IBM Corporation - Chicago, IL).

\section{RESULTS}

During the recruitment period, 54 patients presented to the service to be evaluated. Among these, 51 participants were considered eligible for evaluation, and all of them completed the study. Their mean age was 28 years (with a standard deviation, SD, of 5), most were 36 females (70\%), their mean height was 1.66 meters (SD 0.10), the weight was $68.5 \mathrm{~kg}$ (SD 17.3), and the body mass index (BMI) was $24.5 \mathrm{~kg} / \mathrm{m}^{2}$ (SD 4.5).

Table 1 shows the mean measurements and standard deviations of the MLAA (medial longitudinal arch angle), $\mathrm{NH}$ (navicular height) and FL (Feiss line) in neutral and relaxed positions. The correlation was very strong between the neutral and the relaxed positions of $\mathrm{FL}(r=0.81)$, and moderate for $\mathrm{MLAA}(r=0.78)$ and for $\mathrm{NH}$ $(r=0.76)$, as detailed in Table 2 .

Table 1. Results of the tests in neutral and relaxed positions ( $n=102$ feet).

\begin{tabular}{c|c|c|c}
\hline Test & Mean & Standard deviation & Range \\
\hline MLAA in neutral $\left(^{\circ}\right)$ & 147 & 9 & 120 to 172 \\
\hline MLAA in relaxed $\left(^{\circ}\right)$ & 145 & 8 & 126 to 168 \\
\hline NH in neutral $(\mathrm{cm})$ & 5.1 & 0.7 & 3.3 to 6.7 \\
\hline NH in relaxed $(\mathrm{cm})$ & 4.3 & 0.8 & 2.7 to 6.8 \\
\hline FL in neutral $(\mathrm{cm})$ & -1.8 & 0.8 & -3 to 1.5 \\
\hline FL in relaxed $(\mathrm{cm})$ & -1.7 & 0.9 & -3 to 2.3 \\
\hline
\end{tabular}

MLAA: medial longitudinal arch angle; NH: navicular height and FL: Feiss line. Negative numbers mean the navicular tuberosity was below the line between center of the medial malleolus and the head of the first metatarsus.

\begin{tabular}{|c|c|c|c|c|c|c|}
\hline & $\begin{array}{c}\text { MLAA } \\
\text { neutral }\end{array}$ & $\begin{array}{c}\text { MLAA } \\
\text { relaxed }\end{array}$ & $\begin{array}{c}\mathrm{NH} \\
\text { neutral }\end{array}$ & $\begin{array}{c}\text { NH } \\
\text { relaxed }\end{array}$ & $\begin{array}{c}\text { FL } \\
\text { neutral }\end{array}$ & $\begin{array}{c}\mathrm{FL} \\
\text { relaxed }\end{array}$ \\
\hline MLAA neutral & 1 & & & & & \\
\hline MLAA relaxed & $0.78^{*}$ & 1 & & & & \\
\hline $\mathrm{NH}$ neutral & $1^{*}$ & $0.47^{\star}$ & 1 & & & \\
\hline $\mathrm{NH}$ relaxed & $1^{*}$ & $0.47^{\star}$ & $0.76^{*}$ & 1 & & \\
\hline FL neutral & $0.39^{*}$ & $0.38^{*}$ & $0.25^{\dagger}$ & $0.21^{\dagger}$ & 1 & \\
\hline FL relaxed & $0.40^{*}$ & $0.38^{*}$ & $0.28^{*}$ & $0.24^{\dagger}$ & $0.81^{*}$ & 1 \\
\hline
\end{tabular}

MLAA: medial longitudinal arch angle; NH: navicular height and FL: Feiss line; ${ }^{\star} p<0.01 ;{ }^{\dagger} p<0.05$

\section{DISCUSSION}

To the best of our knowledge, ourthis study is the first assessing the correlation between measurements of the subtalar joint in the neutral and relaxed positions, to evaluate the real need to maintain the two evaluations in the physiotherapeutic routine procedure. A strong correlation was found between the neutral and the relaxed positions of $\mathrm{FL}$, and moderate for MLAA and $\mathrm{NH}$. This correlation suggests that the measurements with the relaxed articulation can predict the results of the measurement with the joint in the neutral position and vice versa.

In our study, we were careful to hide the real objective from the physical therapist performing the evaluation. This evaluator was informed that all measurements should be made considering service routine, i.e., in the neutral and relaxed positions, to assess participants for the inclusion in a clinical study. Therefore, the evaluator was not trying to approximate the two measurements and was, in fact, trying to make accurate measurements. This blinding is a strength of this study.

The measurements of the subtalar joint can be a challenge for the professionals in the neutral position. Specialists are able to find the neutral position more frequently than students in $90 \%$ of the cases..$^{15} \mathrm{~A}$ cadaveric study has also shown that the joint is not really in the neutral when the traditional concept of neutral position is applied by palpation of the lateral and medial aspects of the talus ${ }^{16}$ Maybe this difficulty in performing the evaluation explains why Holmes, Wilcox and Fletcher ${ }^{17}$ found a significant difference between the $\mathrm{NH}$ measurements in neutral and relaxed positions. Scholz et al. ${ }^{18}$ found a high correlation between the arch height index between the neutral and relaxed positions of the subtalar in 172 feet of children, corroborating the findings this study, but in a different population and with a different measurement. Studies ${ }^{16-20}$ aiming to correlate the MLAA measurements with the relaxed subtalar during gait ${ }^{16}$ and race $^{20}$ support phases, measured by 2D kinematics, have found a strong correlation between the measures, concluding that the static measurement in the relaxed position can predict the same measurement in the support phase of the march and the race.

Based on the previous studies and these findings, this study shows that there is no need to use two measures for MLA. Only the measure in the relaxed position is necessary, because this measure is highly correlated with the dynamic measurement. Measuring only once saves time in the evaluation process and expenditures. Measuring the arch in the relaxed position makes the evaluation process more reliable, considering the risk of bias related to the measurement with the subtalar in a neutral position. One limitation of the present study is that the non-zero value before the ruler was not removed, providing a different measure of the real in the measurements of $\mathrm{NH}$ and FL. Another possible limitation 
of our study was that it did not estimate a correlation for the MLA measurements based on participants with a normal, low and high arch, but the normalization of the data was for Danish participants who worked for long periods of standing. ${ }^{9}$ Another limitation is that the sequence of measurement of the ALM was not randomized.

Further studies should address not only the comparison of neutral and relaxed positions but also make these comparisons during dynamic activities such as walking, running, jumping, climbing up and going downstairs, since deformation of the MLA occurs as a result of dynamic activities. Besides comparing static and dynamic measures with the FPI, future studies should seek important clinical correlations, although FPI is a subjective visual evaluation and has a low relation with the dynamic analysis. ${ }^{11}$

\section{CONCLUSION}

Based on the results our study, we conclude that it is not necessary to use measures in the neutral and relaxed position of the subtalar joint, and that the measurement in the relaxed position is enough for the clinical measurements of the medial longitudinal arch.

AUTHORS' CONTRIBUTIONS: Each author contributed individually and significantly to the development of this article. ASP: study design, experimenta study planning, data analysis and interpretation, manuscript writing and final review; DMGN: data interpretation and final review; RDPA: data collection and final review; DGF: study design and critical review of the manuscript; CCJ: study design, data interpretation and manuscript writing; VLSA: study design, experimental study planning and critical review of the manuscript.

\section{REFERENCES}

1. Williamson $P$, Lechtig A, Hanna $P$, Okajima S, Biaggane $P, N a s r ~ M$, et al. Pressure distribution in the ankle and subtalar joint with routine and oversized foot orthoses. Foot Ankle Int. 2018;39(8):994-1000.

2. Buldt AK, Allan JJ, Landorf KB, Menz HB. The relationship between foot posture and plantar pressure during walking in adults: A systematic review. Gait Posture. 2018;62:56-67.

3. Stearne SM, McDonald KA, Alderson JA, North I, Oxnard CE, Ruberson J. The foot's arch and the energetics of human locomotion. Sci Rep. 2016;6:19403.

4. Koldenhoven RM, Feger MA, Fraser JJ, Saliba S, Hertel J. Surface electromyography and plantar pressure during walking in young adults with chronic ankle instability. Knee Surg Sports Traumatol Arthrosc. 2016;24(4):1060-70.

5. Wilson JD, Elis ED, Kernozek TW. Plantar loading characteristics during walking in females with and without patellofemoral pain. J Am Podiatr Med Assoc. 2015;105(1):1-7

6. McKeon PO, Hertel J, Bramble D, Davis I. The foot core system: a new paradigm for understanding intrinsic foot muscle function. Br J Sports Med. 2015;49(5):290.

7. Wezenbeek E, Willems TM, Mahieu N, Van Caekenberghe I, Witvrouw E, De Clercq D. Is Achilles tendon blood flow related to foot pronation? Scand J Med Sci Sports. 2017;27(12): 1970-7.

8. Wezenbeek E, Willems T, Mahieu N, De Muynck M, Bossche LV, Steyaert A, et al. The role of the vascular and structural response to activity in the development of achilles tendinopathy: a prospective study. Am J Sports Med. 2018;46(4):947-54.

9. Nilsson MK, Friis R, Michaelsen MS, Jakobsen PA, Nielsen RO. Classification of the height and flexibility of the medial longitudinal arch of the foot. J Foot Ankle Res. 2012;5:3.
10. Hollander K, Stebbins J, Albertsen IM, Hamacher D, Babin K, Hacke C, Zech A. Arch index and running biomechanics in children aged 10-14 years. Gait Posture. 2018;61:210-4.

11. Paterson KL, Clark RA, Mullins A, Bryant AL, Mentiplay BF. Predicting dynamic foot function from static foot posture: comparison between visual assessment, motion analysis, and a commercially available depth camera. J Orthop Sports Phys Ther. 2015;45(10):789-98

12. Birinci T, Demirbas SB. Relationship between the mobility of medial longitudinal arch and postural control. Acta Orthop Traumatol Turc. 2017;51(3):233-7.

13. Feiss $\mathrm{HO}$. A simple method of estimating the common variations and deformities of the foot. Am J Med Sci. 1909;138(2):213-30.

14. Cook CE, Hegedus EJ. Orthopedic Physical Examination Tests: An Evidence-Based Approach. 2nd ed. New Jersey: Pearson Education; 2013.

15. Pierrynowski MR, Smith SB, Mlynarczyk JH. Proficiency of foot care specialists to place the rearfoot at subtalar neutral. J Am Podiatr Med Assoc. 1996; 86(5):217-23.

16. Chen YX, Yu GR, Mei J, Zhou JQ, Wang W. Assessment of subtalar joint neutral position: a cadaveric study. Chin Med J (Engl). 2008;121(8):735-9.

17. Holmes CF, Wilcox D, Fletcher JP. Effect of a modified, low-dye medial longitudinal arch taping procedure on the subtalar joint neutral position before and after light exercise. J Orthop Sports Phys Ther. 2002;32(5):194-201.

18. Scholz T, Zech A, Wegscheider K, Lezius S, Braumann KM, Sehner S, et al. Reliability and Correlation of Static and Dynamic Foot Arch Measurement in a Healthy Pediatric Population. J Am Podiatr Med Assoc. 2017;107(5):419-27.

19. McPoil TG, Ford J, Fundaun J, Gallegos C, Kinney A, McMillan P, et al. The use of static measure to predict foot posture at midstance during walking. Foot (Edinb). 2016;28:47-53.

20. Bade MB, Chi TL, Farrell KC, Gresl AJ, Hammel LJ, Koster BN, et al. The use of a static measure to predict foot posture at midsupport during running. Int $J$ Sports Phys Ther. 2016;11(1):64-71. 